\title{
A new supercritical co-injection process to coat microparticles
}

\author{
Marilyn Calderone ${ }^{\mathrm{a}}$, Elisabeth Rodier ${ }^{\mathrm{a}, *}$, Hubert Lochard ${ }^{\mathrm{b}}$, \\ Florence Marciacq ${ }^{\mathrm{b}}$, Jacques Fages ${ }^{\mathrm{a}}$ \\ ${ }^{a}$ RAPSODEE Research Centre, UMR EMAC-CNRS 2392, École des Mines d'Albi, Campus Jarlard, 81013 Albi, France \\ ${ }^{\mathrm{b}}$ Pierre Fabre Plantes et Industrie, 16 rue Jean Rostand, 81603 Gaillac, France
}

\begin{abstract}
A new supercritical co-injection process has been developed to coat microparticles. The process was first set up with micron-sized glass beads as model particles and then applied to two powdered active pharmaceutical ingredients. A lipid was used as coating material. The mass balance core/shell in the obtained particles was performed using both differential scanning calorimetry (DSC) and pycnometry measurements and showed a good reproducibility of the process when particles above $20 \mu \mathrm{m}$ size were considered. Fourier transform infrared (FT-IR) spectra and environmental scanning electronic microscope (ESEM) characterization were used to ensure that a shell of coating surrounded the raw particles. Both methods showed a different deposition mode of the lipid between the coated particles and a physical mixture of glass beads and lipid. Release tests in distilled water performed with coated active compounds showed a slowed down dissolution kinetics. The study of the polymorphism of the crystallized lipid revealed a solid/solid transition with time. The supercritical co-injection process is a promising way to discretely coat particles with relatively low diameters $(20-50 \mu \mathrm{m})$ and is particularly suited to coat sensitive pharmaceutical molecules such as proteins.
\end{abstract}

Keywords: Supercritical fluid; Co-injection; Coating; Polymorphism; Lipid; Microparticles

\section{Introduction}

Microencapsulation of active pharmaceutical ingredient (API) is a technique mostly used for controlled or targeted release, in order to mask a bitter taste, to protect a sensitive API from its external environment or to isolate it from another reactive molecule in a pharmaceutical formulation [1]. A review of microencapsulation processes can be found in Ref. [2]. Most of the microencapsulation techniques require organic solvent or involve drastic conditions in terms of temperature, pressure or $\mathrm{pH}$. Besides, it appears that all processes used to coat particles under $50 \mu \mathrm{m}$ have a common feature: the coating agent and the material to be coated are processed into the same media. Hence, sensitive molecules might be degraded during the encapsulation process. For example, the emulsion solvent evaporation process

Abbreviations: API, active pharmaceutical ingredient; BSA, bovine serum albumin; ESEM, environmental scanning electronic microscope; FT-IR, Fourier transform infrared; PE, pseudoephedrine chlorhydrate; SCF, supercritical fluid.

* Corresponding author. Tel.: +33 5634931 25; fax: +33 563493025 .

E-mail address: rodier@enstimac.fr (E. Rodier). is performed by mixing at relatively high temperature both the dissolved active compound and the polymer into the same vessel [3]. Thus, uncoated particles get in contact with the organic solvent used to dissolve the coating polymer, and may suffer from heating. In the fluidization process and its variations such as the Würster one, uncoated particles are fluidized into a chamber where the internal high temperature allows evaporation of the organic solvent and solidification of the coating onto the particles [4]. Consequently, this process might not be suited to thermo sensitive API's.

Supercritical fluids and especially supercritical $\mathrm{CO}_{2}$ display excellent solute properties in a large range of materials and were found to be worthy to generate solvent-free particles [5]. An implementation of this property is well known under the PGSS acronym, particles from gas saturated solution [6]. Briefly, the process involves the dissolution of a dense gas into a liquid or a molten solid until its saturation. The expansion of such a saturated solution or molten phase creates a high super saturation and a sharp temperature decrease leading to particles or droplets formation. After expansion, $\mathrm{CO}_{2}$ becomes gaseous and is easily separated from the processed material. Because organic solvents 
are useless, PGSS is an attractive process for powder generation. It turns out to generate micron- or nano-sized particles with a controlled size range and morphology. Besides, saturating a solid with a high-pressure fluid usually allows to decrease its normal melting point up to $40 \mathrm{~K}$ and thus to lower energetic costs [7].

This principle has been applied for coating applications. For instance, Perrut placed the following uncoated solid APIs: ovalbumin, acid ascorbic or lactase and the coating material, a fat, into the same vessel. The expansion of the mixture caused the solidification of the lipid onto the particles and then the formation of a surrounding shell onto the active compound [8]. Even if the encapsulation was successful, this interesting solvent-free process presents the drawback that the pharmaceutical molecule is heated for a consequent duration in the vessel with the coating. In another implementation of the PGSS process, droplets were coated by a powdered material to allow the handling of a solid form instead of a liquid one [9]. In this case, supercritical $\mathrm{CO}_{2}$ was dissolved in a liquid. The saturated liquid was then expanded to form fine droplets. A powder was carried just at the liquid outlet. The entrapment of liquid droplets by solid particles gave solid-liquid-designed forms. This implementation was named concentrated powder form (CPF) and was applied, for example, to form silica/water-designed particles [10].

The co-injection process presented in this paper is a new route to form microcapsules [11]. It involves first, the dissolution of a pressurized gas into a solid fat in order to easily melt it at relatively low temperatures and second, the expansion of the saturated melted phase and the excess of pressurized fluid onto solid particles. Its main specificity is that the uncoated particles are kept at ambient temperature and therefore, are prevented from any degradation. The contact between the uncoated particles and the pulverized fat occurs in a custom-designed co-injection device, which further allows the deposition of the coating onto the particles. The uncoated particles were conveyed to the coinjection device by a Venturi system alimented by pressurized air. Alternatively conveying the particles with pressurized $\mathrm{CO}_{2}$ from a high-pressure vessel was also experimented. The chosen coating agent was Precirol ${ }^{\circledR}$, a commercial mixture of di- and triglycerides. In a first time, the process was applied to glass beads as model particles; then it was tested to coat cohesive active compounds. The polymorphism of the crystallized fat was also investigated during shell life. Indeed, it is well established that fatty products may exhibit ageing effect, whereby a range of physical properties may change during storage [12].

\section{Materials and methods}

Precirol $^{\circledR}$ ATO 5 (Glycerol dipalmitostearate, Gattefossé, France) was used as coating material for this study. Precirol ${ }^{\circledR}$ is a mixture of mono-, di- and triglycerides and contains mainly a diglyceride (51.6 wt \%) with one C16 $(48.9 \%)$ and one $\mathrm{C} 18$ $(48.8 \%)$ fatty acid saturated chains. Precirol ${ }^{\circledR}$ is widely used as filler into pharmaceutical formulations and is found to be safe $[13,14]$.

$\mathrm{CO}_{2}$ N45 TP was supplied by Air Liquide (99.6\% pure, Air Liquide, France) and used as supplied.
Because of their spherical shape, controlled size and smooth surface, glass beads $(0-80 \mu \mathrm{m}$, Sovitec, France) were first used as model particles. They were considered as model in terms of flow ability, controlled size distribution and non-cohesive behaviour. Before coating experiments, glass beads were sieved into the six following size fractions: $<20,20-30,30-40,40-50$, 50-63 and 63-80 $\mu \mathrm{m}$. Pseudoephedrine chlorhydrate (PE) and bovine serum albumin (BSA) were supplied by Pierre Fabre Laboratories (Plantes et Industries, France). PE is a white cohesive powder, whereas BSA particles are large translucent pellets.

\subsection{Characterization of particles size, shape and morphology}

A thin film deposited onto the particles must lead in an increase of their average diameters. Thus, particle size and particle size distribution were determined before and after the coating experiments. Particle diameter was measured using an Aerosizer ${ }^{\circledR}$ PSD 3603 particle size distribution analyser (TSI, USA). This apparatus measures the time it takes for a particle to be accelerated through two laser beams, in a fixed laminar flow. It is accurate for the lower part of the size distribution (under $100 \mu \mathrm{m}$ ); in the higher part, a big single particle may diffract significantly laser beam thus perturbing the measurement. As a consequence, the average volume diameter, $D[4 ; 3]$, can be mistaken, and we have chosen to evaluate the change in particle size considering the median diameter $D_{50}$, which is less affected by this perturbation. The results are presented together with the cumulated volume size distributions and with regard to the distribution span. The span is defined by the following relation $\left(D_{90}-D_{10}\right) / D_{50}$, and reflects the width of the distribution [15]. A particle size distribution analysis of these results was presented in Ref. [16].

ESEM, environmental scanning microscope XL 30 FEG (Philips, Netherlands) was used to visualize the deposition of Precirol ${ }^{\circledR}$ onto the particles. Samples were sputter coated with gold 2-nm thick, in high vacuum, using a sputter coater prior to SEM analysis.

$\mathrm{X}$-ray powder diffraction patterns of the starting materials and the coated glass beads were recorded on a X'pert diffractometer (Philips, Netherlands), at a scan rate of $0.5^{\circ} \mathrm{min}^{-1}$ over the range $2-40^{\circ}$. Samples were analyzed in duplicate.

Infrared spectra were recorded with a 2000 FT-IR equipped Spectrum V.5.0.1 software (PerkinElmer, UK). Disks were obtained by grinding $100 \mathrm{mg}$ of dry $\mathrm{KBr}$ with $1 \mathrm{mg}$ of studied sample. Spectra were acquired in the range $4000-400 \mathrm{~cm}^{-1}$.

\subsection{Characterization of product composition}

Differential scanning calorimetry DSC 7 (PerkinElmer, UK) allowed to quantify the mass of deposited Precirol ${ }^{\circledR}$ onto the particles. For DSC measurements, a sample of about $5 \mathrm{mg}$ was placed into an aluminium DSC pan. The temperature increases from 293.15 to $363.15 \mathrm{~K}$ at a heating rate of $5 \mathrm{~K} / \mathrm{min}$ under nitrogen flow. The amount of Precirol ${ }^{\circledR}$ was determined from the relation (1): 
$x=\frac{\Delta H_{\text {melting }}^{\text {coating agent onto the sample }}}{\Delta H_{\text {melting }}^{\text {pure coating agent }}}$

In (1), $x$ represents the mass ratio of the coating agent in the coated particles. $\Delta H_{\text {melting }}^{\text {coating agent onto the sample }}$, is the heat of fusion of Precirol ${ }^{\circledR}$ in the coated particles samples. $\Delta H_{\text {melting }}^{\text {pure coating agent }}$, is the heat of fusion of Precirol ${ }^{\circledR}$ solidified alone via the same supercritical fluid process. Relation (1) allows quantification of Precirol ${ }^{\circledR}$ deposited onto the particles, but the measurement was done on a small fraction of the coated sample.

Then, quantification of the whole collected coated samples was performed via true density measurement using a helium pycnometer Accupyc 1330 (Micromeritics, USA). Density measurements of $d_{i}$ give an evaluation of the mass ratio of coating agent, $f_{\text {coating agent }}$, according to the relation (2)

$\frac{1}{d_{\text {coated particle }}}=\frac{f_{\text {coating agent }}}{d_{\text {coating agent }}}+\frac{1-f_{\text {coating agent }}}{d_{\text {uncoated particle }}}$

\subsection{Measurements of intrinsic dissolution rates}

The coated samples dissolution tests were performed as follows: five fractions of a given sample were placed into five flasks equipped with a magnetic stirrer and stirred at $100 \mathrm{rpm} .50 \mathrm{~mL}$ of distilled water at room temperature were introduced in each flask. An aliquot per flask was collected at different time intervals and filtered using Millex LH PTFE $0.45 \mu \mathrm{m}$ filters (Millipore, USA). The UV absorption at $258 \mathrm{~nm}$ was then measured with a HP 8452A (PerkinElmer, UK).

\section{Coating experiments: experimental set-up and procedure}

Pressure and temperature conditions of crystallization of the coating material were studied in [17]. Briefly, the previous study showed that the Precirol ${ }^{\circledR}$ melting point could be decreased of $20 \mathrm{~K}$, by solubilizing a dense gas in it. Precirol ${ }^{\circledR}$ normal melting point was measured by calorimetry at $329.6 \pm 0.4 \mathrm{~K}$. The maximum melting point depletion was reached for pressures equal to $11 \mathrm{MPa}$ or above. Thus, in all the following coating experiments we fixed the pressure of the vessel at $11 \mathrm{MPa}$.

The experimental set-up is depicted in Fig. 1. Before starting the experiments, uncoated particles were put into the container of a Venturi GVP12 (Coval, France) pressurized by an air injection system at $0.7 \mathrm{MPa}$ pressure. Solid Precirol ${ }^{\circledR}$ was placed into a high-pressure vessel and the process was then ready to start. $\mathrm{CO}_{2}$ coming from the cylinder (1), was liquefied (2) to be pumped (3), then flowed through a heat exchanger (4) in order to be heated at $323.15 \mathrm{~K}$. Supercritical $\mathrm{CO}_{2}$ was then introduced into the vessel (5) at $11 \mathrm{MPa}$, whereabouts it started to dissolve into solid Precirol ${ }^{\circledR}$ and melted the fat. The $\mathrm{CO}_{2}$ flowed continuously for $30 \mathrm{~min}$ so as to reach equilibrium, while the pressure was maintained at $11 \mathrm{MPa}$. The saturated melted phase and an additional excess of supercritical $\mathrm{CO}_{2}$ were then next expanded through a valve at the Venturi inlet pressure. At the same time of this expansion, the valve (7) was opened to allow the pneu-

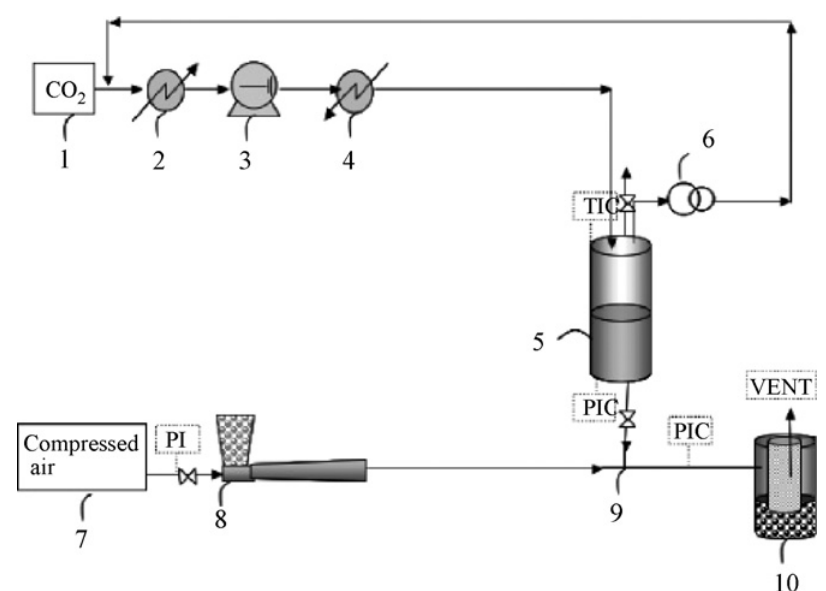

Fig. 1. Sketch of the co-injection coating process: the Venturi is used as bare particles conveying system.

matic conveying (8) of the uncoated particles to the co-injection device. Uncoated particles and expanded Precirol ${ }^{\circledR}$ get then into contact in a designed co-injection device (9), as shown in Fig. 2. Due to the high supersaturation generated, Precirol ${ }^{\circledR}$ solidified onto the particles. The coated particles were then conveyed to a gas/solid separation filter (10). Gases escaped through the vent line, whereas the coated particles were collected into the separator for further analysis.

In another implementation of the previously described coinjection process, carbon dioxide was both used as carrying and solute gas, which allowed its re-use. Therefore uncoated particles were placed into a vessel filled up by gaseous $\mathrm{CO}_{2}$ at $2 \mathrm{MPa}$ pressure. The coating process procedure was similar: when melted Precirol ${ }^{\circledR}$ was expanded, a valve at the bottom of the vessel containing the raw particles was opened to push the material towards the co-injection device.

\section{Results and discussion}

\subsection{Preliminary experiments}

Before performing the coating experiments, both Precirol ${ }^{\circledR}$ and glass beads were processed alone. Crystallization of the lipid by supercritical fluid was necessary to determine the average size of the so-formed particles and gave information on the

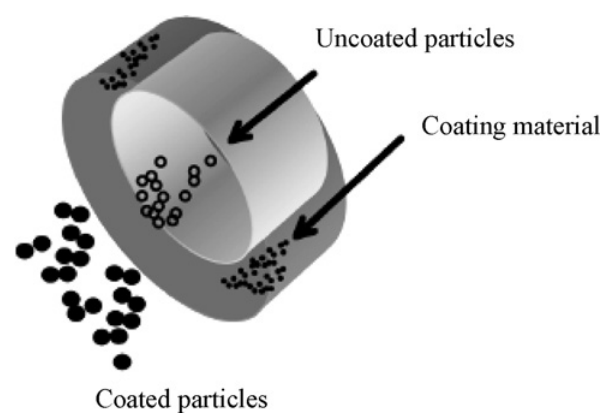

Fig. 2. The co-injection device ensure the contact between the uncoated particles and the coating material expanded from the high-pressure vessel. 
Table 1

Preliminary experiments: study of the SCF crystallization of Precirol ${ }^{\circledR}$ and impact of the pressure on the glass beads diameter

\begin{tabular}{ll}
\hline Samples & $D[4 ; 3](\mu \mathrm{m})$ \\
Precirol $^{\circledR}$ solidified by a SCF process & $12.2 \pm 0.4$ \\
Unprocessed Precirol $^{\circledR}$ & $43.0 \pm 1.1$ \\
Glass beads before injection & $45.9 \pm 0.1$ \\
Glass beads after injection at 80 bars pressure & $46.1 \pm 0.3$ \\
\hline
\end{tabular}

polymorph obtained. Processing the particles through pressurized $\mathrm{CO}_{2}$ was unavoidable to ensure that the conveying did not alter particles.

When processing Precirol ${ }^{\circledR}$, the experimental conditions have been given previously. Unprocessed fat particles have a mean volume diameter of $43.0 \pm 10.1 \mu \mathrm{m}$, whereas recrystallized ones have a worthy lower mean volume diameter of $12.2 \pm 0.4 \mu \mathrm{m}$ (Table 1). The heat of fusion of re-crystallized Precirol ${ }^{\circledR}$ was measured by DSC immediately after its processing and was found to be $114.4 \pm 1.3 \mathrm{~J} / \mathrm{g}$. This value was the reference chosen for mass ratio calculation according to relation (1).

As for the glass beads, the high-pressure vessel (6) was filled with glass bead particles and flowed to the co-injection device under gaseous carbon dioxide at a pressure of $8 \mathrm{MPa}$. The particle size distribution was measured before and after this treatment, so as to check that the process does not alter the particles, neither by attrition nor by agglomeration (Table 1 ). Since a pressure of $8 \mathrm{MPa}$ has no significant effect on the particles diameter, we assumed that there is no altering effect when particles were injected at a lower pressure.

\subsection{Coating of the sieved glass beads: study of the homogeneity of a processed sample and of the reproducibility of the coating process}

Fig. 3 depicts an example of particle size measurements obtained on the $50-63 \mu \mathrm{m}$ sieved glass bead fraction. Trials one and two correspond to the same experiment repeated twice: $3 \mathrm{~g}$ of Precirol ${ }^{\circledR}$ were put in the autoclave and $3 \mathrm{~g}$ of glass beads were injected by the compressed air alimented Venturi. The curves are

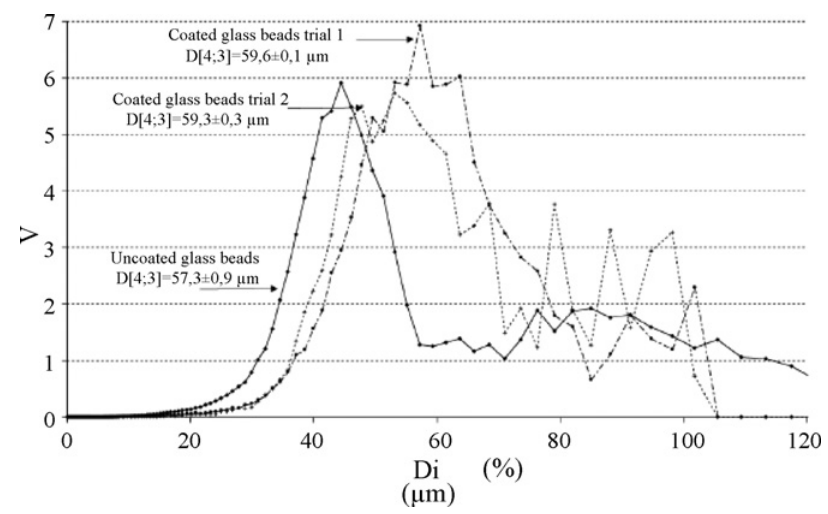

Fig. 3. Particle size distribution in volume percentage for the coated and uncoated $50-63 \mu \mathrm{m}$ glass beads. The experiment was done using the Venturi as bare particle conveying device. noised by the diffraction of the greatest particles. The standard deviation given for the mean volume diameter was calculated on the basis of three particles size measurements performed on the same sample. Considering both standard deviations of uncoated and of coated particles, it appears that the coated samples get a higher diameter than the uncoated ones. This may be due to the deposit of a film of Precirol ${ }^{\circledR}$ onto the particles. This assumption is verified by ESEM investigations. Fig. 4(a) shows uncoated glass beads, whereas Fig. 4(b) and (c) depict coated ones. Fig. 4(d) focuses on the surface of a coated glass bead. A crystallized fat layer can be seen on the bead surface.

The next three coating trials were performed on the smallest particles, i.e. under $20 \mu \mathrm{m}$. In this case, the particles were injected using gaseous $\mathrm{CO}_{2}$. Precirol ${ }^{\circledR}$ supplied weight percentage was equal to $33.3 \%$ of the total weight coating/glass beads. The three coating experiments were analyzed by particle size distribution, DSC and pycnometry.

Results for reproducibility discussion are depicted in Table 2. The median diameter $D_{50}$ of coated glass beads was $16.0 \pm 1.0 \mu \mathrm{m}$, whereas the $D_{50}$ of bare particles was $13.4 \pm 0.4 \mu \mathrm{m}$. The standard deviations on the entire population given were calculated on three different trials. Based on these values, the reproducibility of the process, on this first parameter was good. Considering now the mass percent determined by DSC according to relation (1), the weight of Precirol ${ }^{\circledR}$ deposited onto the particles was evaluated at $19.2 \pm 4.1 \%$. This value was significantly lower than the one obtained by pycnometry according to Eq. (2): $27.7 \pm 3 \%$. Consequently, the relative uncertainty of the co-injection process based on mass balance criteria was $10.9 \%$ when pycnometry characterization was performed, but reached $21.6 \%$ on the basis of the DSC measurements. The difference between the results given by these two methods can be explained if one considers that DSC was performed on the 1000th part of a coated sample and pure Precirol ${ }^{\circledR}$ aggregates were segregated in the whole sample and not taken for the DSC measurement. Thus, DSC gave information on the mass of fat deposited onto the particles excluding fat in excess. On the opposite, pycnometry was done on the whole sample. Therefore this measure took into account the present lipid, deposited or not onto the particles.

The value obtained, when compared to the global mass balance, gives then a piece of information on the Precirol ${ }^{\circledR}$ that was lost in the experimental set-up during co-injection process. As the initial quantity of Precirol ${ }^{\circledR}$ loaded was $33.3 \%$ in weight and the overall final percentage in the coated beads was $21.6 \%$, about $12 \%$ of fat has been lost throughout the coating experiment. That somewhat important loss was thought to be technology dependant: indeed, the downstream Precirol ${ }^{\circledR}$ coming from the expansion valve flows through a right angle before reaching the expansion device of Fig. 2. Therefore, this dead area can retain a few coating material.

\subsection{Comparison of the coated glass beads with a physical mixture?}

At this step, comparing the coated glass beads sample lower than $20 \mu \mathrm{m}$, with a physical mixture of the same weight ratio, 

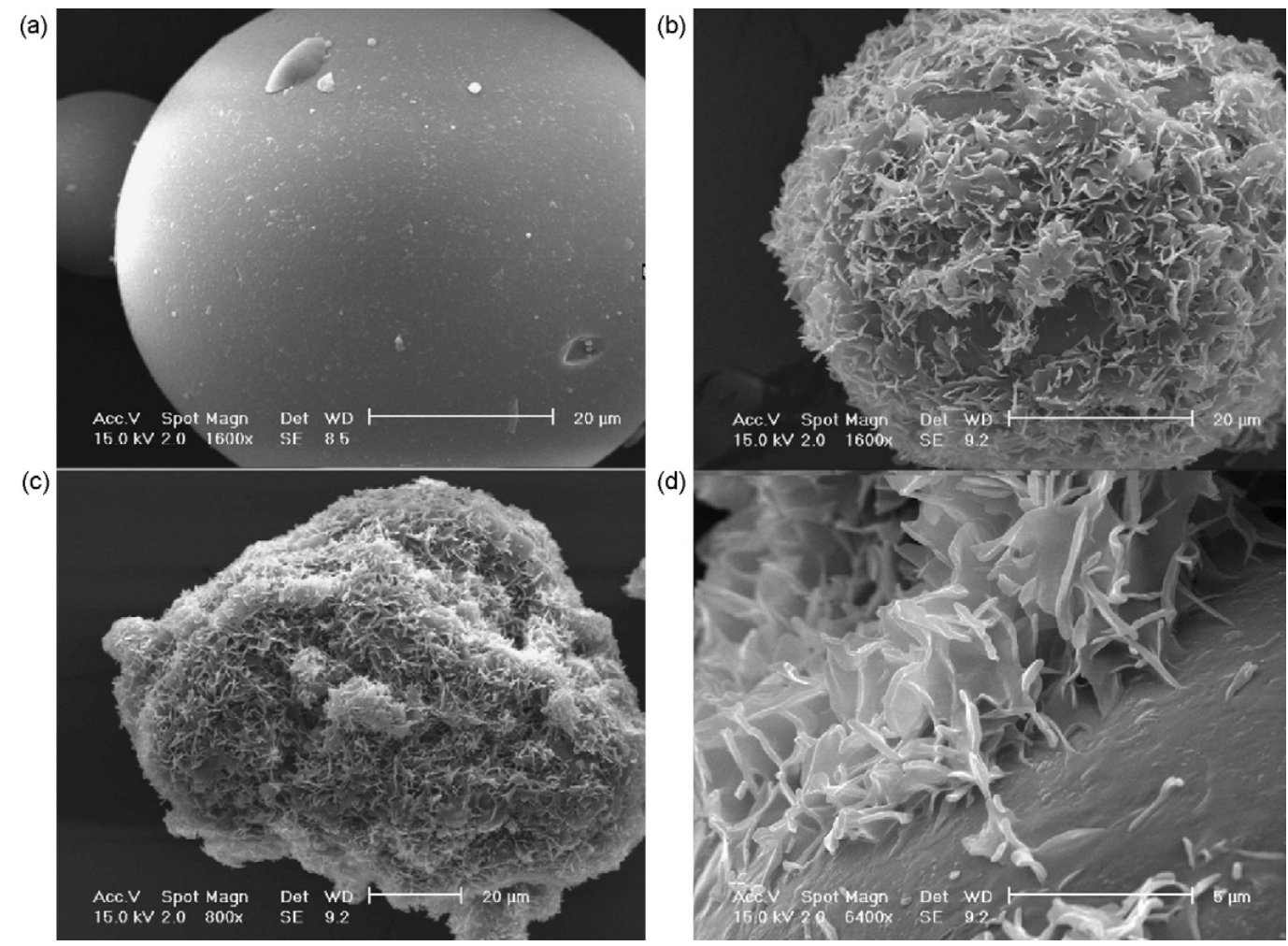

Fig. 4. MEBE photographs of the 50-63 $\mu \mathrm{m}$ glass bead fraction. (a) Uncoated glass bead magnification $1600 \times$; (b) coated glass bead magnification $1600 \times$; (c) coated glass beads magnification $800 \times$; (d) coated glass beads magnification $6400 \times$.

brought interesting additional information. Therefore, Precirol ${ }^{\circledR}$ solidified by supercritical $\mathrm{CO}_{2}$ was strongly mixed manually with the smallest glass beads to form the so-called physical mixture. The weight ratio (coating:beads) chosen for the physical mixture was the one measured by DSC on the coated sample: $19.2 \mathrm{wt} \%$. Since the expanded Precirol ${ }^{\circledR}$ should surround the glass beads in the coated sample, a single population, was then expected. Whereas the physical mixture, that contained two free separate compounds, should present two different particles populations. As a result, FT-IR spectra of the physical mixture should be the addition of the Precirol ${ }^{\circledR}$ peaks and the glass beads ones, whereas the coated sample should diffract only the fat molecule. A fraction of the obtained samples was visualized by ESEM (Fig. 5) and presented some differences: the fat crystallized on the glass beads surface for the co-injected sample, whereas it was just deposited on the surface in the physical mixture. Obviously, the FT-IR spectra of the physical mixture differed from the coated sample ones as depicted in Fig. 6: especially, characteristic peaks of silica element found in the $3200-3600$ and $400-800 \mathrm{~cm}^{-1}$ regions were hidden in the coated glass beads sample, whereas they were present in the physical mixture sample, giving evidence that the fat form a shell onto the glass beads surface.

Table 3 presents results for particle size distribution analysis. An example of an obtained distribution is plotted in Fig. 7 for the $20-30 \mu \mathrm{m}$ size range. On this figure, trials $1-3$ were replica of the same experiment. Similar $D_{50}$ were obtained and curves were transposed towards higher diameters between the bare sample and the coated ones. Higher $D_{50}$ on coated glass beads samples were also found for particles size class above $20 \mu \mathrm{m}$ (Table 3 ).

Table 2

Study of the reproducibility of the co-injection process: results of three similar coating experiments

\begin{tabular}{|c|c|c|}
\hline Method & Experimental results & Conclusion \\
\hline Particle size analysis & $\begin{array}{l}\text { Coating experiments: } D_{50} \text { trial } 1=15.8 \mu \mathrm{m} ; D_{50} \text { trial } 2=17.3 \mu \mathrm{m} \text {; } \\
D_{50} \text { trial } 3=15.0 \mu \mathrm{m} ; D_{50} \text { uncoated beads }=13.4 \pm 0.4 \mu \mathrm{m}\end{array}$ & $D_{50}$ coated particles: $16.0 \pm 1.0 \mu \mathrm{m}$ \\
\hline $\begin{array}{l}\text { DSC (supplied Precirol }{ }^{\circledR} \\
\quad \text { percentage: } 33.3 \% \text { ) }\end{array}$ & 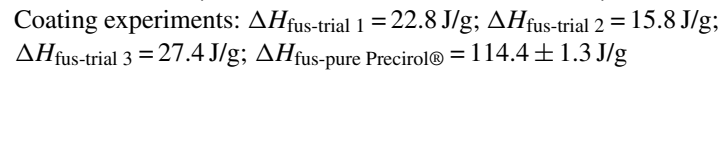 & $\begin{array}{l}\text { Mass percent of Precirol }{ }^{\circledR} \text { trial } 1=19.9 \% \text {; mass ratio of } \\
\text { Precirol }{ }^{\circledR} \text { trial } 2=13.8 \% \text {; mass ratio of Precirol }{ }^{\circledR} \text { trial } \\
3=23.6 \% \text {; average trials }(1-3)=19.2 \pm 4.1 \% \text {; relative } \\
\text { uncertainty }=21.6 \%\end{array}$ \\
\hline $\begin{array}{l}\text { Pycnometry (supplied } \\
\text { Precirol }{ }^{\circledR} \text { percentage: } \\
33.3 \% \text { ) }\end{array}$ & $\begin{array}{l}\text { Density measurements: } \rho_{\text {trial } 1}=1.78 \mathrm{~g} / \mathrm{cm}^{3} ; \rho_{\text {trial } 2}=1.79 \mathrm{~g} / \mathrm{cm}^{3} ; \\
\rho_{\text {trial } 3}=1.89 \mathrm{~g} / \mathrm{cm}^{3} ; \rho_{\text {glass beads }}=2.45 \mathrm{~g} / \mathrm{cm}^{3} ; \rho \\
\text { Precirol }{ }^{\circledR}=0.99 \mathrm{~g} / \mathrm{cm}^{3}\end{array}$ & $\begin{array}{l}\text { Mass ratio of Precirol }{ }^{\circledR} \text { trial } 1=29.9 \% \text {; mass ratio of Precirol }{ }^{\circledR} \\
\text { trial } 2=29.8 \% \text {; mass ratio of Precirol }{ }^{\circledR} \text { trial } 3=23.4 \% \text {; average } \\
\text { trials }(1-3)=27.7 \pm 3 \% \text {; relative uncertainty }=10.9 \%\end{array}$ \\
\hline
\end{tabular}


(a)

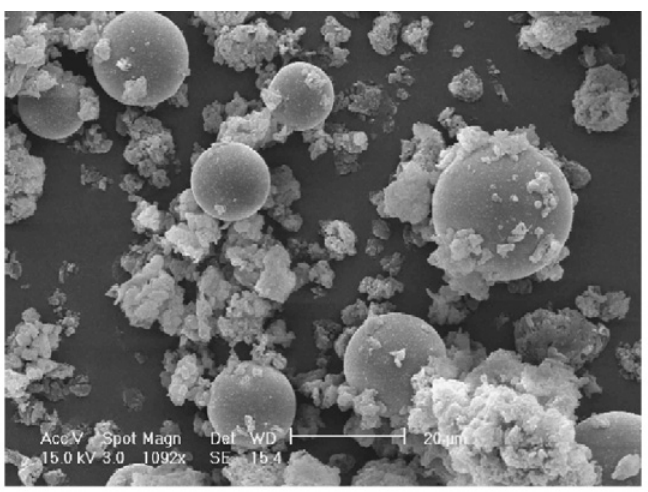

(c)

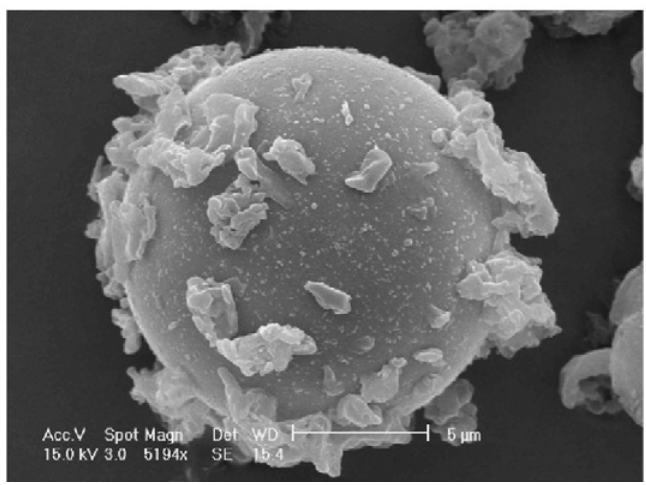

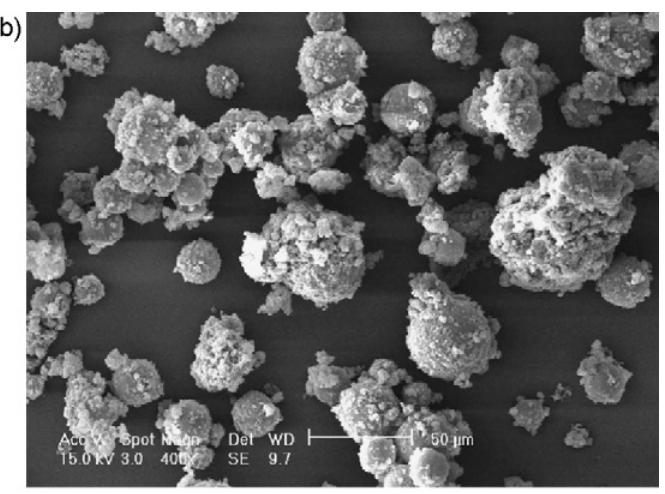

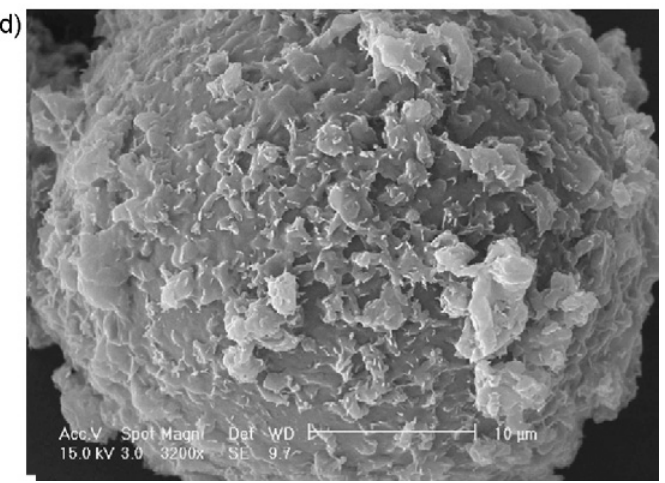

Fig. 5. MEBE comparison of a physical mixture glass beads/Precirol ${ }^{\circledR}$ and a coated sample. (a) Physical mixture magnification $1092 \times$; (b) coated sample magnification $400 \times$; (c) physical mixture magnification $5194 \times$; (d) coated sample magnification $3200 \times$.

For each mean diameter class the specific surface area of the uncoated glass beads was calculated using relation (3):

$S_{\text {calculated }}=\frac{6}{D[3 ; 2]} \frac{1}{\rho_{\text {glass beads }}}$

Glass beads being spherical, the surface diameter $D[3 ; 2]$ is equal to the volume diameter $D[4 ; 3]$. Values of the weight of Precirol ${ }^{\circledR}$ deposited onto the particles, which was measured by DSC, enabled to quantify each experiment in terms of deposited mass of Precirol ${ }^{\circledR}$ per glass beads surface area, as presented in Table 4. This ratio was plotted versus the specific surface area (Fig. 8). The results showed a good linear correlation for the smallest surface areas between deposited quantity of Precirol ${ }^{\circledR}$

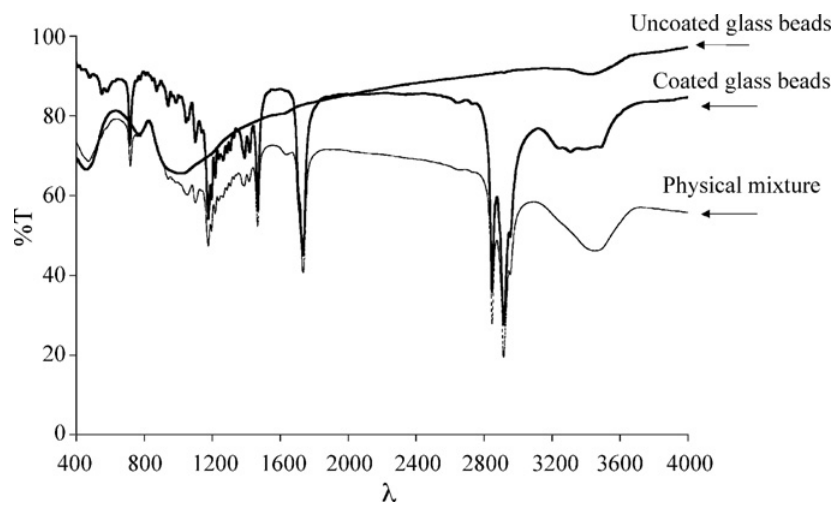

Fig. 6. FT-IR spectra of coated particles and of physical mixture.
Table 3

Comparison between the $D_{50}$ of the coated and uncoated glass beads and for the five sieved class

\begin{tabular}{|c|c|c|c|c|}
\hline \multicolumn{3}{|c|}{ Uncoated glass beads } & \multicolumn{2}{|c|}{ Coated glass beads } \\
\hline $\begin{array}{l}\text { Sieved } \\
\text { class }(\mu \mathrm{m})\end{array}$ & $D_{50}(\mu \mathrm{m})$ & $\begin{array}{l}\text { Uncoated glass } \\
\text { beads span }\end{array}$ & $D_{50}(\mu \mathrm{m})$ & $\begin{array}{l}\text { Coated glass } \\
\text { beads span }\end{array}$ \\
\hline$<20$ & 13.4 & 1.9 & $16 \pm 1$ & $1.06 \pm 0.08$ \\
\hline $20-30$ & 27.2 & 0.53 & $29.3 \pm 0.3$ & $0.51 \pm 0.12$ \\
\hline $30-40$ & 31.9 & 0.43 & $36.9 \pm 3.6$ & $0.46 \pm 0.02$ \\
\hline $40-55$ & 45.9 & 0.36 & $51.2 \pm 1.1$ & $0.43 \pm 0.02$ \\
\hline $55-80$ & 59.3 & 0.37 & $65.4 \pm 1.5$ & $0.41 \pm 0$ \\
\hline
\end{tabular}

per surface area and the surface area or the diameter of the beads. This implies an individual coating for the lowest surface areas particles that is to say the highest particle sizes. On the contrary, the correlation was no longer valid for the highest specific

Table 4

Volume of deposited Precirol ${ }^{\circledR}$ per glass bead surface unit and for the five sieved fractions

\begin{tabular}{|c|c|c|c|c|}
\hline \multicolumn{3}{|c|}{ Coated glass beads } & \multicolumn{2}{|c|}{ Coating quantification } \\
\hline $\begin{array}{l}\text { Sieved class } \\
(\mu \mathrm{m})\end{array}$ & $D[4 ; 3](\mu \mathrm{m})$ & $\begin{array}{l}S_{\text {calculated }} \\
\left(\mathrm{m}^{2} / \mathrm{g}\right)\end{array}$ & $\begin{array}{l}\text { Precirol }^{\circledR} \\
(\mathrm{wt} \%)\end{array}$ & $\begin{array}{l}\mathrm{cm}^{3} \text { Precirol }{ }^{\circledR} / \mathrm{m}^{2} \\
\text { glass beads }\end{array}$ \\
\hline$<20$ & $17.5 \pm 0.8$ & 0.14 & $22.9 \pm 4.8$ & 2.60 \\
\hline $20-30$ & $28.8 \pm 0.1$ & 0.09 & $23.4 \pm 10.1$ & 3.47 \\
\hline $30-40$ & $39.4 \pm 1.3$ & 0.07 & $24.1 \pm 2.4$ & 4.23 \\
\hline $40-55$ & $50.4 \pm 0.8$ & 0.06 & $22.3 \pm 1.8$ & 5.22 \\
\hline $55-80$ & $62.9 \pm 2.6$ & 0.04 & $20.8 \pm 0.9$ & 6.40 \\
\hline
\end{tabular}




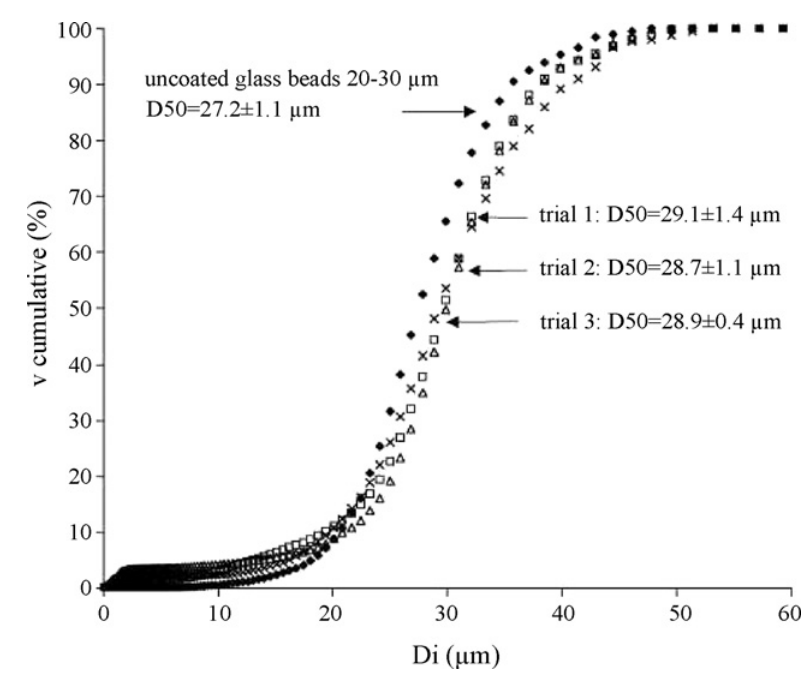

Fig. 7. Particle size distribution in cumulated volume for the $20-30 \mu \mathrm{m}$ class coated glass beads. The experiment was done using the Venturi as bare particle conveying device.

surface areas, or the smallest particles. This may be due to an agglomeration effect. These results were consistent with the span values obtained before and after coating: the span was narrower for the smallest specific surface areas but wider for the highest ones (Table 3).

\subsection{Validation of the co-injection process: coating of the micron-sized APIS-PE and BSA}

Before starting the coating experiments, raw BSA mean volume diameter was measured to be $69.6 \pm 11.4 \mu \mathrm{m}$ by Aerosizer ${ }^{\circledR}$ particle size measurements, whereas raw PE mean diameter was measured at $16.1 \pm 1.2 \mu \mathrm{m}$. Besides, particle size distribution showed a large polydispersity for this compound, which was confirmed by microscopy. In all the following coating experiments, the ratio (coating:active ingredient) was chosen equal to 1. A sample of $3 \mathrm{~g}$ of the coating fat was co-injected with a sample of $3 \mathrm{~g}$ of an active compound using a Venturi as conveying system. Both BSA and PE coating experiment were repeated twice.

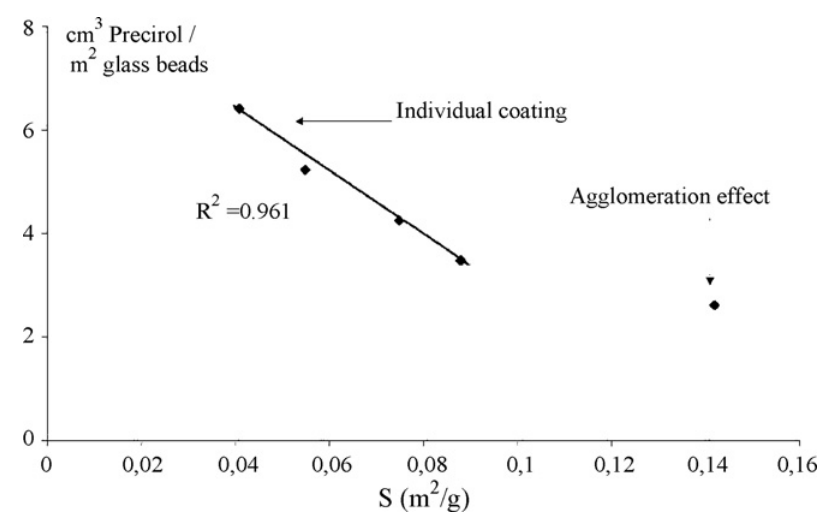

Fig. 8. Volume of Precirol ${ }^{\circledR}$ deposited on the particles vs. the specific surface area of the particles.
ESEM characterization evidenced agglomeration on coated PE samples (Fig. 9). This effect could be proactively expected from Fig. 8, indeed raw PE mean volume diameter was $16.1 \pm 1.2 \mu \mathrm{m}$. Agglomeration was not surprising due to the powder characteristics: cohesive particles, diameter under $15 \mu \mathrm{m}$, widely dispersed.

Particle size distribution analysis corroborated the agglomeration phenomenon: trials 1 and 2, in Fig. 10, were the replica of the same experiment but samples median diameters were significantly different. This is due to a random agglomeration of PE with lipid. Besides, in both trials, the coated samples had a significant higher median diameter compared to the uncoated API. This might be due to both agglomeration and coating effects as evidenced on ESEM pictures of Fig. 9. The agglomeration phenomenon may occur during the transport through the coinjection device system or after the coating in the solid/gas separator. Concerning, the mass percent determined by DSC, it gave an average Precirol ${ }^{\circledR}$ percentage of 59.1 and $77.3 \%$ for respectively trials 1 and 2, whereas the initial fat mass percent was $50 \%$. Agglomeration phenomenon was taken responsible for too high the amount of lipid, dosed by DSC.

Finally, drug release tests performed on coated BSA and PE in distilled water at room temperature both presented slower dissolution rate compared to raw materials (Figs. 11 and 12). Whereas uncoated PE was fully dissolved within $10 \mathrm{~min}$, coated PE (trial 1) needed five times more to be released in water and PE processed in trial 2 was released in $150 \mathrm{~min}$. So, Precirol ${ }^{\circledR}$ deposited on the surface by this new process was effective enough to slow down the release of the active compound in distilled water. The coated PE from trial 2, which had the highest percentage of Precirol ${ }^{\circledR}$ took a longer time to be released in water. As for coated BSA, the compound was completely released within 30 min into distilled water, whereas uncoated one was fully dissolved in water within $5 \mathrm{~min}$ at room temperature.

\subsection{Some considerations about the ageing of the fat crystallized by supercritical fluid}

The last part of the study aimed to determine if the very low temperature reached when expanding the fat and the associated high cooling rate may affect the structure of Precirol ${ }^{\circledR}$. Indeed, the in situ measured depressurization temperature was close to $243 \mathrm{~K}$.

A sample of Precirol ${ }^{\circledR}$ was crystallized by supercritical route and stored at room temperature. Its heat of fusion was measured at regular time intervals. Fig. 13 shows the evolution of the temperatures of the melting peaks. The heat of fusion of the fat increased from $114.4 \mathrm{~J} / \mathrm{g}$ for a freshly crystallized sample up to $170 \mathrm{~J} / \mathrm{g}$ after 1 year of ageing. The fresh sample presented one single peak, whereas the aged sample developed a second peak towards the highest temperatures. This remark suggested a reorganization of the crystalline lattice of the fatty compound. Fig. 14 depicts Precirol ${ }^{\circledR}$ X-ray diffraction patterns. The large single peak for freshly solidified Precirol ${ }^{\circledR}$ developed rapidly a shoulder on its left side and then two others peaks on each side of the first main one. After 74 days, Precirol ${ }^{\circledR}$ spectrum exhibited four distinct peaks identified at $4.25 \AA$ which was the 
(a)

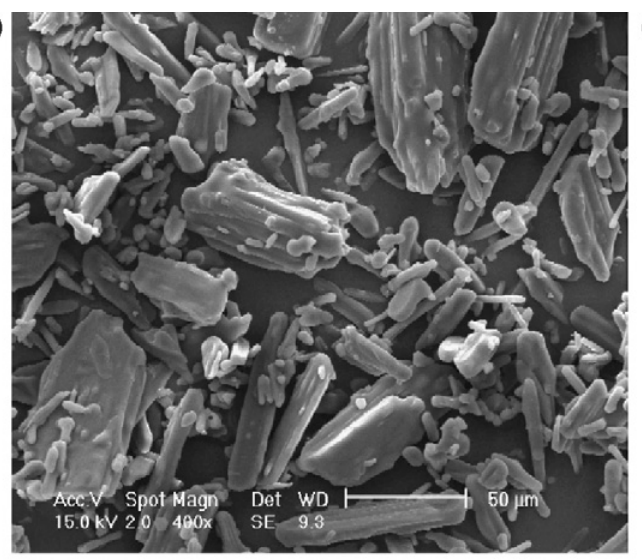

(c)

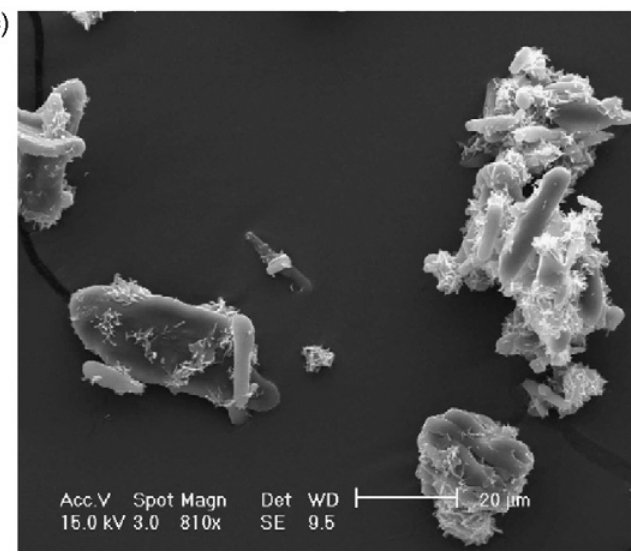

(b)

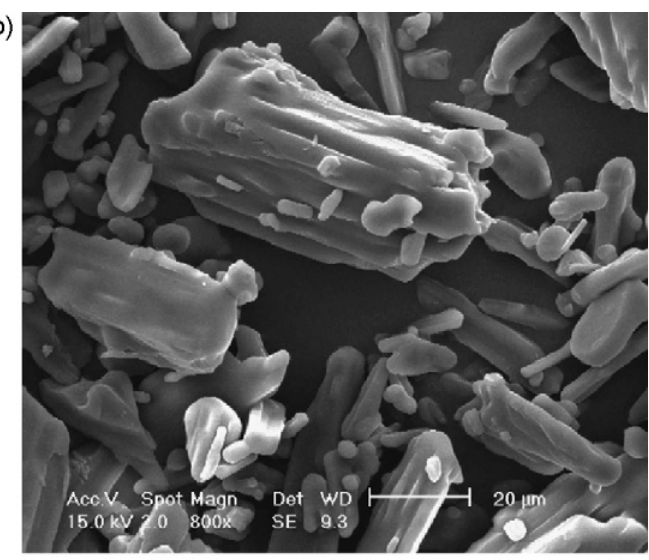

(d)

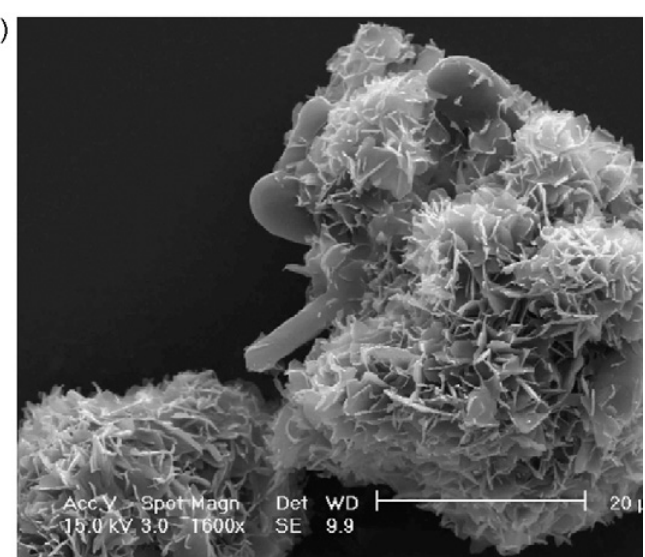

Fig. 9. ESEM pictures of the pseudoephedrine chlorhydrate (PE) coated or not, by the Precirol ${ }^{\circledR}$. (a) Raw PE magnification $490 \times$; (b) raw PE magnification $800 \times$; (c) coated sample magnification $810 \times$; (d) coated sample magnification $1600 \times$.

first to appear, 4.67 and 5.16 that were the following, and 3.93 that was the fourth one. After 193 days two additional peaks seemed to appear, at 3.78 and $4.35 \AA$ while the 4.25 one had significantly decreased. Sato established that triglycerides may be subject to solid/solid transitions: $\alpha$ form of triglyceride gives one single strong peak at $4.15 \AA, \beta^{\prime}$ form peak is usually recognized by its two peaks, at 3.8 and $4.2 \AA$, whereas three peaks at 4.6 (strong), 3.8 (weak) and 5.4 (weak) would be characteristic for the $\beta$ form [18]. $\alpha, \beta^{\prime}, \beta$ correspond to different subcell

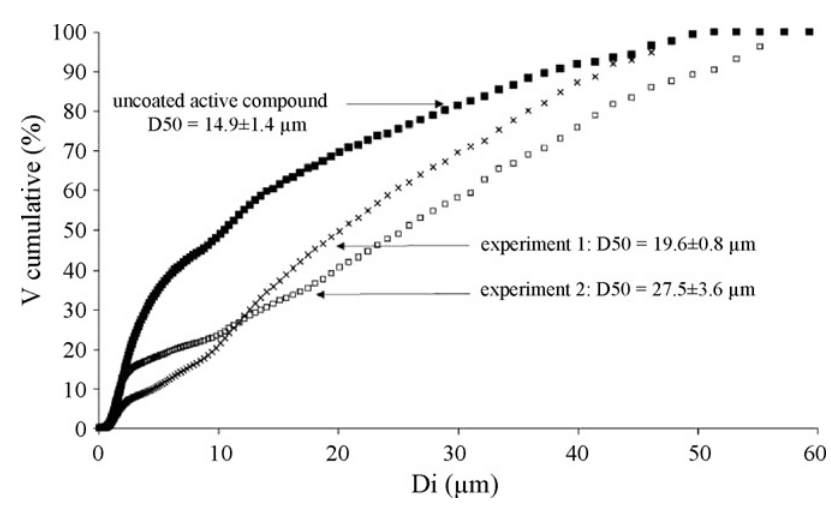

Fig. 10. Particle size distribution in cumulated volume for the pseudoephedrine chlorhydrate coating tests. Trials 1 and 2 are the replica of the same experiment. crystalline structures. $\alpha$ is the thermodynamically less stable form, whereas $\beta$ is usually the most stable one for pure triglycerides, whereas it could be the $\beta^{\prime}$ form for triglycerides mixtures. Less information can be found on diglycerides in the literature. According to Sato [19], $\beta^{\prime}$ form would not exist for 1,2 saturated monoacid diglycerides, whereas the three forms, $\alpha, \beta^{\prime} \beta$ were evidenced in the case of 1,3 saturated monoacid diglycerides. On the hypothesis that Precirol ${ }^{\circledR}$ main component is a

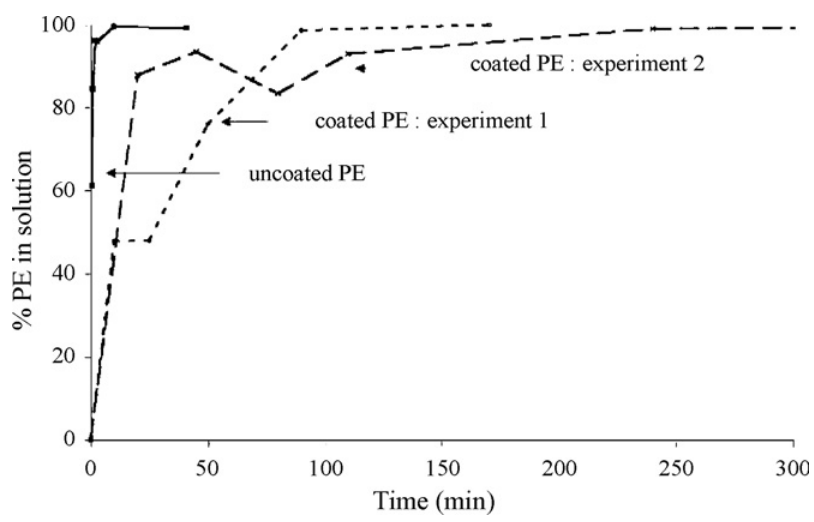

Fig. 11. Test release of the coated pseudoephedrine chlorhydrate and the raw one in distilled water and at room temperature. 


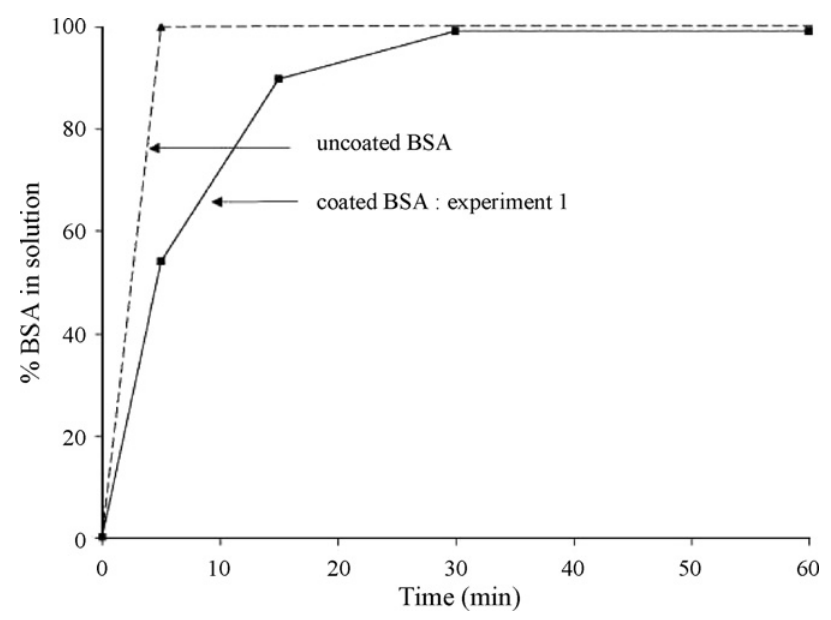

Fig. 12. Test release of the coated BSA and the raw one in distilled water and at room temperature.

1,3 diglyceride, the one crystallized by supercritical fluid might then be composed of a $\alpha$ form that evolved with time into a $\beta$ form; at least a $\beta^{\prime}$ form seemed to appear. This evolution was relatively fast when the fat was stored at room temperature but was significantly slower, about 4 months, when stored in cooled conditions (i.e. $277.15 \mathrm{~K}$ ). Furthermore, Precirol $^{\circledR}$ freshly supplied get the same heat of fusion as Precirol ${ }^{\circledR}$ just after crystallization by SCF. Further re-crystallization tests (not presented in this paper), were done with a DSC apparatus performing heating/cooling/heating cycles, the lowest temperature ranging from 273.15 to $223.15 \mathrm{~K}$ the highest being $363.15 \mathrm{~K}$ and varying cooling rates from 5 to $15 \mathrm{~K} / \mathrm{min}$. These tests showed that the heat of fusion obtained at the second heating and the re-crystallization temperature during the cooling step varied slightly and remained close to $114.4 \mathrm{~J} / \mathrm{g}$ (actually, between 114 and $123 \mathrm{~J} / \mathrm{g}$ ) and 328.7 K (between 328.69 and 329.11 K). From all these remarks, it appears that Precirol ${ }^{\circledR}$ was somewhat influenced by the conditions of solidification. The fact that Precirol ${ }^{\circledR}$ is a mixture of fats and not a pure compound, might be the reason of such a stability.

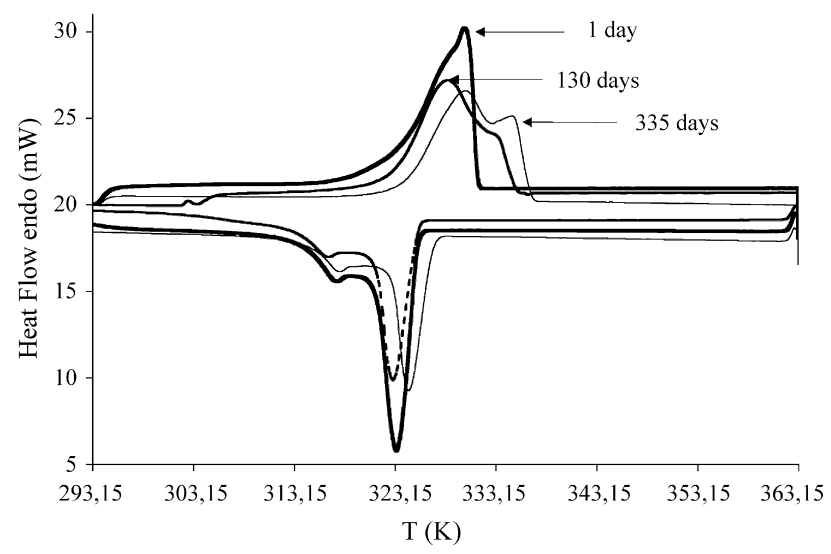

Fig. 13. Time course evolution over 335 days of the DSC spectra of Precirol ${ }^{\circledR}$ stored at room temperature.

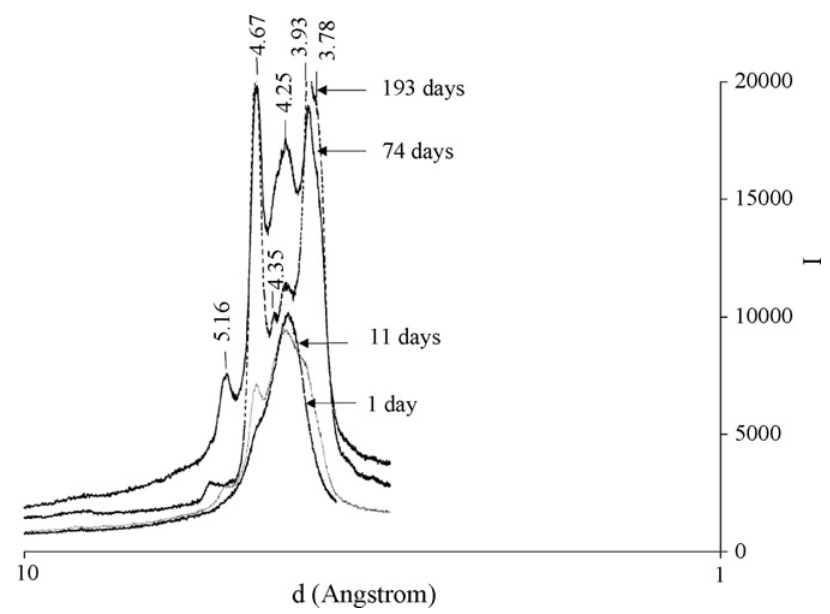

Fig. 14. X-ray powder diffraction pattern of Precirol ${ }^{\circledR}$ stored at room temperature at different time intervals.

\subsection{Some considerations about this new process}

From the above results and discussion we can sum up the main novelties and advantages of the proposed process. First, it is a green process as it does not use any organic solvent, contributes to valorise the main greenhouse effect gas and $\mathrm{CO}_{2}$ can be re-used in the process. Besides, the two-step process, dissolution-expansion, is proposed here in a semi-continuous configuration: it could be achieved in a continuous way by considering a separation of the coated particles from the uncoated ones and from exceeding coating agent (through cyclonic separators for instance) and then a recirculation of the coated particles up to the Venturi tank and re-use of the coating agent. Third, it allows to coat particles that are tricky to fluidize, under $80 \mu \mathrm{m}$ and above $20 \mu \mathrm{m}$, without any agglomeration problem, in particular, for non-cohesive powders. Finally, labile materials can be processed in this way without any degradation and the coating agent is processed at operating temperatures below the ones used at atmospheric conditions, which is worthy in terms of energetic yield. On a scaling-up point of view, the ratio of coating agent to particles would have to be considered as the main invariant.

Yet, several points has been underscored that need to be well controlled. The right angle just before the expansion valve must be suppressed, thus the fat loss will be drastically reduced and the relative uncertainty of the process improved. The mass ratio of coating agent to particles has also to be controlled: it could be achieved tuning the bare particles flow rate. This would allow both a precise control of the quantity of fat, which deposits onto the host particles and a limited agglomeration phenomenon as well, since it will have no excess of fat in the coated samples. For highly cohesive powders, particles agglomeration can be reduced, by using dry compressed air as venturi alimentation. Experiments (not presented here) with a dessicator just prior the venturi inlet have shown a reduction of the agglomeration. As for the coating agent processing, the upstream (before expansion) temperature and pressure determine the phase of the coating agent downstream (after expansion), but the excess of 
supercritical $\mathrm{CO}_{2}$ upstream has also a major influence on the temperature after expansion and on the nature of the expanded coating agent [20]. So upstream operating conditions have to be chosen so as the whole the lipid is melt and the maximum depletion of the melting point is reached. In addition, the excess quantity of $\mathrm{CO}_{2}$ has to be carefully chosen in order to control the downstream conditions and the nature of the expanded product.

\section{Conclusion, further work}

A new co-injection process for coating fine particles by fats under supercritical conditions has been developed. This process can be implemented both by conveying the initial particles in air using a Venturi system or with a gaseous stream of $\mathrm{CO}_{2}$. The first study done with Precirol ${ }^{\circledR}$ and glass beads showed that both techniques are valuable, but need further improvements since the fat deposit measured by DSC $(19.2 \pm 4.1 \%)$ may vary in rather large proportion. In terms of encapsulation quality, the co-injection process differs whether high or low specific surface area particles are coated. For the lowest surface areas (50-63 $\mu \mathrm{m}$ range size particles), a good correlation between the mass deposited and the surface available for the fat was found. In this case, particles were rather discretely coated as confirmed by ESEM pictures. For the highest surface area (particles smaller than $20 \mu \mathrm{m}$ ), this correlation was no longer valid, and agglomeration was the dominant phenomenon. In any case, FT-IR and ESEM observations evidenced clear differences between a physical mixture and a processed coated sample; the latter exhibited in all cases a much better coating. The validation of the co-injection process was done with two active compounds, PE (pseudoephedrine chlorhydrate) and BSA (bovine serum albumin). Both compounds presented significant lowered dissolution rates once the particles are processed and coated by the fatty material.

The last point of the study dealt with the supercritical crystallization of the fatty product. Indeed, the co-injection coating process sharply and quickly cooled down the fat at negative temperature. The study showed that Precirol ${ }^{\circledR}$ was stable in terms of crystallization and followed a solid-solid transition from $\alpha$ to $\beta$ or $\beta^{\prime}$ form, independently of the solidification pathway.

The co-injection coating process involves neither high temperature nor organic solvent for the APIs to be coated. Hence, this process is mostly suited to coat sensitive molecules such as proteins. Besides a good control of both flow rates coating/particles is allowed, thus the thickness of the surrounding shell could be adapted. When only $\mathrm{CO}_{2}$ is used, the gas can be fully re-used. The co-injection process is currently under scaling up phase.

\section{Acknowledgements}

We would like to thanks the Pierre Fabre Company for financial support via Performances project. We thank Sylvie Del Confetto for DSC measurements and Philippe Accart for particle size distribution analyses and their profitable discussion.

\section{Appendix A. Nomenclature}

$d_{i} \quad$ density of the compound $i\left(\mathrm{~kg} / \mathrm{m}^{3}\right)$

$D[4 ; 3]$ mean volume diameter $(\mathrm{m})$

$D_{50} \quad$ median diameter $(\mathrm{m})$

$f_{i} \quad$ mass fraction of the compound $i$

$\Delta H_{\text {fus }}$ heat of fusion $(\mathrm{J} / \mathrm{g})$

$S_{0} \quad$ specific surface area, $\mathrm{m}^{2} / \mathrm{g}$

\section{References}

[1] G. Cole, J. Hogan, M. Aulton, Pharmaceutical Coating Technology, Taylor \& Francis (ed.), London, 1995.

[2] D. Chulia, M. Deleuil, Y. Pourcelot, Powder technology and pharmaceutical processes, in: Handbook of Powder Technology, vol. 9, Elsevier Science (ed.), Amsterdam, 1994, p. 513.

[3] A. André-Abrant, J.L. Taverdet, J. Jay, Microencapsulation par évaporation de solvant, Eur. Polym. J. 37 (2001) 955-963.

[4] H. Ichikawa, Y. Fukumori, Microagglomeration of pulverised pharmaceutical powders using the Wurster process. I. Preparation of highly drug-incorporated, subsieve-sized core particles for subsequent microencapsulation by film coating, Int. J. Pharm. 180 (1999) 195-210.

[5] J. Fages, H. Lochard, J.-J. Letourneau, M. Sauceau, E. Rodier, Particle generation for pharmaceutical applications using supercritical fluids technology, Powder Technol. 141 (2004) 219-226.

[6] E. Weidner, Z. Knez, Z. Novak, PGSS (Particles from Gas Saturated Solutions) - a new process for powder generation, in: G. Brunner, M. Perrut (Eds.), Proceedings of the 3rd International Symposium on Supercritical Fluids, Strasbourg, 1994, pp. 229-234.

[7] E. Weidner, V. Wiesmet, Z. Knez, M. Skerget, Phase equilibrium (solid-liquid-gas) in polyethylenglycol carbon dioxide systems, J. Supercrit. Fluids 10 (1997) 139-147.

[8] M. Perrut, Method for encapsulating fine solid particles in the form of microcapsules, WO Patent 02/05944 A1, 2002.

[9] B. Weinreich, R. Steiner, Method for producing powder product from a liquid substance or mixture of substances, EP Patent 1021241 A, 2000.

[10] H. Lankes, K. Sommer, B. Weinreich, Liquid absorption capacity of carriers in the food technology, Powder Technol. 134 (2003) 109-201.

[11] M. Calderone, E. Rodier, Pierre Fabre Medicament, Method for coating powders, WO Patent 06/030112, 2006.

[12] W. Sutanata, D.Q.M. Craig, J.M. Newton, The effects of ageing on the thermal behaviour and mechanical properties of pharmaceutical glycerides, Int. J. Pharm. 111 (1994) 51-62.

[13] V. Jannin, E. Pochard, O. Chambin, Influence of poloxamers on the dissolution performance and stability of controlled-release formulations containing Precirol ${ }^{\circledR}$ ATO 5, Int. J. Pharm. 309 (2006) 6-15.

[14] M. Savolainen, J. Herder, C. Khoo, K. Lovqvist, C. Dahlqvist, H. Glad, A.M. Juppo, Evaluation of polar lipid hydrophilic polymer microparticles, Int. J. Pharm. 262 (2003) 47-62.

[15] T. Allen, Particle size measurement Powder Sampling and Particle Size Measurement, 1, Vth ed., Chapman \& Hall (ed.), London, 1997.

[16] M. Calderone, E. Rodier, J. Fages, Microencapsulation by a solvent-free supercritical fluid process: use of density, calorimetric and size analysis to quantify and qualify the coating, Part. Sci. Technol. 42 (2007) 189-199.

[17] A.R. Sampaio de Sousa, M. Calderone, E. Rodier, J. Fages, C.M.M. Duarte, Solubility of carbon dioxide in three lipid-based biocarriers, J. Supercrit. Fluids 39 (2006) 13-19.

[18] K. Sato, Crystallization behaviour of fats and lipids - a review, Chem. Eng. Sci. 56 (2001) 2255-2265.

[19] K. Sato, in: N. Garti, K. Sato (Eds.), Crystallization and Polymorphism of Fats and Fatty Acids, Marcel Dekker, New York, 1988.

[20] M. Calderone, E. Rodier, J.-J. Letourneau, J. Fages, Solidification of Precirol ${ }^{\circledR}$ by the expansion of a supercritical fluid saturated melt: from the thermodynamic balance towards the crystallization aspect, J. Supercrit. Fluids 42 (2) (2007) 189-199. 